\title{
The impact of stakeholder engagement on local policy decision making
}

\author{
Le Anh Nguyen Long ${ }^{1,2} \cdot$ Megan Foster $^{1} \cdot$ Gwen Arnold $^{1}$
}

Published online: 9 September 2019

(c) The Author(s) 2019

\begin{abstract}
We investigate how grassroots stakeholder engagement in municipal meetings shapes the decision making of local elected officials (LEOs) by examining the choices LEOs in New York State made on how to regulate high-volume hydraulic fracturing (HVHF) or fracking. We analyzed the content of 216 meeting minutes and 18 policy documents for 13 municipalities in New York. Our observations suggest that government responsiveness to local activism is shaped by the level of contestation between grassroots stakeholders. They reveal that contestation among grassroots stakeholders encourages LEOs to try to deflect responsibility for regulating fracking. When this contestation is high, LEOs tend to pursue actions which may limit but not prohibit HVHF within their jurisdiction. In contrast, when there is no contestation, LEOs more actively pursue substantive policy actions that prohibit HVHF. Generally, we find that that the level of contestation among grassroots stakeholders about HVHF impacts the political actions LEOs take.
\end{abstract}

Keywords Decision making · Grassroots stakeholders · Local activism · Local officials · Hydraulic fracturing · Blame avoidance

\section{Introduction}

Scholars are increasingly interested in municipal government forays into environmental policymaking. The resulting body of work has opened a window into how the behaviors of grassroots stakeholders and policy advocates shape policy processes and outcomes (Arnold et al. 2017; Few et al. 2007; Lubell 2004b). However, it has paid considerably less attention to the impacts of this advocacy on the actors charged with making the decisions that establish policies: local elected officials (LEOs). To address this gap, this paper examines

Le Anh Nguyen Long

lnlong@ucdavis.edu

1 Department of Environmental Science and Policy, University of California, Davis, 2144 Wickson Hall, One Shields Avenue, Davis, CA 95616, USA

2 Chair of International Relations and Sustainable Development, Institute of Political Science, University of Münster, Scharnhorststrasse 100, 48151 Münster, Germany 
the interplay between grassroots stakeholder engagement and LEO strategic behavior, and how these dynamics impact local environmental policymaking.

LEOs are increasingly tasked with regulating environmental concerns that do not conventionally lay within the purview of local government, and for which local governments do not typically command the practical, material, and political resources critical for problem resolution (Agranoff and McGuire 2001; Lemos and Agrawal 2006; Marshall 2008). This lack of familiarity and capacity is challenging for LEOs who already balance numerous concerns while negotiating and coordinating with diverse stakeholders, including peers from local government; municipal employees; county, state, and national-level public officials; private citizens; businesses; and civil society actors (Arnold and Nguyen Long 2018; Boin and t'Hart 2003; Howlett 2014a). Grassroots stakeholder participation may improve LEO accountability and knowledge about how to tackle environmental governance challenges (Devas and Grant 2003; Vigoda 2002).

Stakeholders are affected by policy, affect policy, or both (Freeman 1984; Grimble and Wellard 1997). Many types of actors and entities, from public agencies to corporations, hold a stake in environmental policy making. What distinguishes grassroots stakeholders from other stakeholders is that the former "are the people who actually consume natural resources" (Lubell 2004a, b: 342). We extend this definition to include the consumption of environmental amenities, such as groundwater or clean air, and to specify that grassroots stakeholders are "rooted in the scale of everyday experience" (Towers 2000: 23). Grassroots stakeholders draw legitimacy and authority on an environmental issue from their firsthand knowledge of and experience with the implicated natural resources.

In local government policymaking, affected residents are the grassroots. Since Arnstein published her path-breaking work on citizen participation in governance in 1969, support for the engagement of grassroots stakeholders in environmental policymaking has grown and spread widely. ${ }^{1}$ While grassroots stakeholder participation is widely theorized to improve policymaking (Fischer 2000; Beierle 2002, 2010), it remains unclear how effective it is in shaping policy processes and outcomes (Reed 2008; Few et al. 2007; Irvin and Stansbury 2004).

Stakeholders often have heterogeneous preferences, but their ability to coalesce around an issue and speak with an uncontested and unified voice may affect the efficacy of their advocacy (Rein and Schön 1977). More specifically, stakeholder engagement can lie in a continuum of contestation. On one end of this continuum, grassroots engagement can be uncontested, where stakeholders are unified on one side of an issue. To varying degrees along the continuum, grassroots engagement can be contested, where different stakeholders press LEOs to pursue different actions. Contestation intensifies as the frequency with which directly opposing sides challenge one another and decision makers on an issue increases and/or as the duration of these contests lengthens.

We posit that not only does stakeholder engagement shape policymaking, but the degree of contestation - a feature of stakeholder engagement - can systematically influence how LEOs treat policy issues. Examining this proposition provides insight into how the dynamics between grassroots stakeholders themselves may influence LEO behavior, adding nuance to the current understanding of whether and how citizen engagement impacts policy design (Howlett 2014b, 2017; Gormley 1986; Smith and McDonough 2001). Moreover, accounting for the impact that contestation can have on policymaking may reveal insights

${ }^{1}$ One example is the EPA's Community Based Environmental Protection (CBEP) program. 
into the challenges of collaborative governance. Collaborative governance is an increasingly institutionalized approach to natural resource management (Emerson et al. 2012; Bingham et al. 2005). While contestation between stakeholders has been identified as a critical barrier to successful collaborative governance (Ansell and Gash 2008), few collaborative governance studies focus specifically on the nature of these conflicts or the specific processes by which they influence policy outcomes. The few studies that have examined these conflicts tend to focus on single case studies (Berardo and Holm 2018), making them unable to examine the breadth of actions decision makers can take when confronting different levels of grassroots contestation on an issue.

To test the proposition that contestation impacts LEO choices, we examine how LEOs in New York responded to stakeholder engagement around the issue of high-volume hydraulic fracturing (HVHF), a new technique for recovering hydrocarbons trapped in deep underground shale deposits (Rahm 2011). From 2008 through 2012, 235 municipalities across the state adopted 358 anti-HVHF policies (Arnold and Nguyen Long 2018), often in response to concerns over the technology's potential environmental and public health impacts. During that same period, more than 60 pro-fracking regulations were adopted by New York municipalities, often encouraged by landowners with drilling interests and economic development advocates who argued that HVHF was a lifeline for the state's struggling rural communities. New York partially overlays the Marcellus Shale, whose potential hydrocarbon production was projected to create more than 54,000 jobs in the state (Rugh 2012; Jacquet and Stedman 2011). While previous research has revealed how institutional, geophysical, and demographic factors may have contributed to New York localities' policy choices concerning HVHF (e.g., Dokshin 2016), LEO influence on these processes and outcomes remains minimally understood.

We use content analysis of minutes taken at public meetings (i.e., town board meetings) as well as policy documents to examine 13 cases of municipal consideration of $\mathrm{HVHF}$, 2008-2012. The extent and nature of stakeholder engagement in HVHF policymaking varied substantially across these cases. Our observations suggest that LEOs respond to stakeholder engagement in a patterned way. Contested stakeholder engagement appears to encourage LEOs to deflect responsibility for HVHF regulation to other bodies of government. Contestation also appears to discourage LEOs from placing substantive limits on HVHF, especially when contestation is intense. In contrast, LEOs respond to uncontested anti-HVHF stakeholder engagement by prohibiting HVHF within their jurisdiction. In contrast to previous work that views stakeholder engagement as either effective or ineffective (see Reed 2008), we provide a more nuanced picture.

\section{Local contestation over HVHF in New York}

The State of New York instituted a moratorium on HVHF in 2008. The moratorium's duration was unclear and, as it ensued, the state's regulatory approach became increasingly opaque (Arnold and Nguyen 2018). Pro- and anti-fracking advocates responded to this uncertainty by seeking to influence local government policymaking on HVHF, relying on New York's tradition of strong home rule (Kenneally and Mathes 2010). As the debate on HVHF intensified and widened, numerous stakeholders brought their HVHF demands directly to the attention of local elected officials. Measures to ban or restrict HVHF were frequently sought by tourism interests, concerned that drilling would reduce visitor interest (DeWitt 2012); environmentalists concerned about contaminated groundwater, air 
pollution, and habitat destruction (Dutzik et al. 2013); and residents were concerned about quality-of-life impacts. In contrast, members of landowner coalitions, ${ }^{2}$ business and industrial interests, and economic development advocates pressured municipalities to adopt HVHF-supportive policies (Smith and Ferguson 2013; Jacquet 2015).

LEO efforts to steer HVHF governance were complicated by the technical and political ambiguity surrounding the new drilling technology. Technical ambiguity arises from persistent disputes among experts which subsequently divide a policymaking community. Some scientific experts argued that HVHF threatens water resources and contributes to greenhouse gas emissions (Howarth et al. 2011). Others countered that HVHF-associated risks can be contained through careful management (Jackson et al. 2014), and that HVHF is a valuable bridge to renewable energy and a pathway to energy security (Engelder 2011). Anti- and pro-HVHF interests brought conflicting scientific evidence to bear and called in their own "experts" to speak on the issue (Dodge and Lee 2015). As a consequence, scientific evidence was often treated with skepticism by local policy participants, and its infusion into debates over HVHF generally failed to bring clarity (Dodge and Lee 2015). In one town board meeting, residents and LEOs disagreed about the value of scientific evidence:

Mr. Goukas [resident] offered a name of a Geologist out of Cornell that has put together findings of potential outcomes from gas drilling in NY State. Mr. Denton [LEO] said that there is a schism between Cornell Departments. Ms. Grant [another resident] said that one thing that she has learned from statistics is that whatever you want to believe you can show. (Town of Colesville board meeting, Aug. 2, 2012)

About 80 miles away, similar views on scientific evidence were voiced by a grassroots stakeholder, making the case for action: "Even if you think it's safe, new information [is] coming out month after month. Why wait to act?" (Town of Hector board meeting, March 13, 2012).

Technical ambiguity compounded the political ambiguity faced by New York LEOs. Officials considering policy actions other than non-substantive resolutions-that is, considering measures with more regulatory "teeth," such as bans-were unsure about their jurisdiction over HVHF, since oil and gas drilling was typically regulated at the state level (Arnold and Nguyen Long 2018; Kenneally and Mathes 2010). Uncertainty about municipal authority over HVHF policymaking and two high-profile legal challenges against New York municipalities that did try to ban $\mathrm{HVHF}^{3}$ were key concerns for LEOs. Resource-strapped municipalities pondering anti-HVHF action were unsure about how to construct policies that could withstand legal challenge (Negro 2012). For example, in the Town of Delaware, LEO Harold Roeder cautioned that developers with "deep pockets" could take legal action if the town took substantive action against HVHF (Town of Delaware board meeting, April 20, 2011). In the Town of Hector, LEO Jeff Magnus informed the public that, "there is still the legal issue/aspect; two of

\footnotetext{
${ }^{2}$ Landowner coalitions are groups that formed around the interest of local landowners seeking to lease their land to the natural gas industry (Jacquet and Stedman 2011).

3 In 2011, two lawsuits - one brought by landowner Jennifer Huntington against the Town of Middlefield and another brought by Norse Energy Corporation and Cooperstown Holstein Corporation against the Town of Dryden-challenged New York municipalities' authority to regulate HVHF within their jurisdictions. The spike in local anti-HVHF policy adoptions that followed the New York Supreme Court decision in favor of Middlefield and Dryden suggests that the outcome of these cases was on the radar of New York LEOs.
} 
three lawyers at Association of Towns seminar answered questions regarding lawsuits with-if you feel lucky in the legal arena then ban fracking; [but] I am not elected to gamble with your money" (Town of Hector board meeting, February 14, 2012). Contemporaneously, demand for local policy action regarding HVHF, both favorable and unfavorable, continued to grow, placing additional pressures on LEOs (Arnold and Nguyen Long 2018).

\section{Theorizing the influence of contested and uncontested stakeholder engagement on LEOs}

In keeping with previous scholarship on decision making by elected officials (e.g., McGraw 1990, 1991), we assume that LEOs are primarily motivated by electoral performance. It follows that LEOs will adopt strategies that help them claim credit for positive policy outcomes and avoid blame for policies which constituents might perceive as failures (Leong and Howlett 2017; Howlett 2012; Hood 2002, 2007, 2011).

LEOs may be more responsive to grassroots stakeholders than their peers in state or national government because local officials are relatively easier for grassroots stakeholders to monitor, observe, and access. Additionally, LEOs may be relatively more sensitive to these stakeholder's ability to "vote with their feet," choosing to live elsewhere if they do not approve of LEO policy choices (see Tiebout 1956; Sharp 1984). Electoral considerations may encourage public officials to preemptively act on what they perceive to be the preferred policies of the largest share of the electorate (Johnson and Crisp 2003). To do so, however, LEOs must have a clear sense of the actions that those constituents consider desirable and praiseworthy (Leong and Howlett 2017). For example, LEOs from cities with fairly liberal residents may adopt more numerous and stringent environmental policies to cater to known preferences of liberal constituencies (e.g., Sharp et al. 2011; Zahran et al. 2008). However, intense political ambiguity breeds uncertainty about citizen preferences. Moreover, technical ambiguity makes it difficult for LEOs to predict how their choices might impact their constituents in the future. Risk-adverse LEOs can be expected to take what Howlett (2014a, b) calls negative action, which in this case would be to deny that HVHF is a local issue. Ambiguity thus often favors the policy status quo.

In New York, the status quo was to defer to the state on the regulation of oil and gas production, including HVHF. Local action on HVHF was novel, controversial, and potentially legally questionable. It was rational for LEOs to wait for the state to take action on HVHF rather than making themselves vulnerable to controversy and legal liability. Without pressure from grassroots stakeholders to act on HVHF, there was little incentive for LEOs to deviate from the status quo. Thus, we expect that when there is no stakeholder engagement, LEOs will not act on HVHF (Proposition 1).

Once the public engages, however, maintaining the status quo becomes more difficult. When members of the public primarily array on one side of HVHF (most members of the public in favor of HVHF, or most members against it), we consider the stakeholder engagement to be uncontested. When these interests battle each other, however, we consider stakeholder engagement on HVHF to be contested; this contestation can vary in duration and intensity. This variance in stakeholder engagement is particularly salient to LEOs' use of policy action. 


\section{Grassroots stakeholder engagement and LEO policy action}

For LEOs grappling with ambiguity, uncontested stakeholder engagement clarifies the actions that would be electorally beneficial versus costly for the LEO by clearly signaling stakeholders' preferences (Adams 2004). In other words, the electorally beneficial path toward issue resolution is clearer when stakeholders are uncontested. We therefore reason that uncontested stakeholder engagement provides LEOs with a convenient list of "demands which are clearly defined and bureaucratically obtainable" (Rubin 1988, 236). This knowledge eases decision-making burdens and can be treated as a "checklist" with which LEOs can "make progress" on HVHF, an otherwise ambiguous policy situation. Essentially, grassroots stakeholders are clients to whom LEOs respond by providing swift and accurate service (Vigoda 2002).

When uncontested stakeholders demand policy actions that limit or prohibit drilling, they make claims on officials to take action and essentially raise the political costs of negative actions (Felstiner et al. 1980). Three policy types placed substantive limits on HVHF (Arnold and Nguyen Long 2018). Road use policies restrict HVHF or require remuneration for damage to local infrastructure. Moratoriums and bans placed restrictions directly on HVHF, albeit temporarily in the case of moratoriums. Claims-making by uncontested grassroots stakeholders raises the likelihood that LEOs will be blamed for inaction on HVHF. Thus, we expect that LEO adoption of substantive anti-HVHF policy actions is more likely when engagement is uncontested (Proposition 2.1).

Unlike uncontested grassroots engagement, ambiguity around the political consequences of taking action on HVHF is not mitigated when grassroots stakeholder engagement is contested. Contested publics speak with a fragmented voice, presenting LEOs with a rigmarole of often conflicting demands, all the while raising LEO awareness of how salient the issue is to their constituents. Together, these dynamics raise ambiguity.

Ambiguity offers decision makers an opportunity to redefine the boundaries of authority on a political issue (Daviter 2015). The goal of boundary redefinition may be to gain power and authority over an issue, or to deflect responsibility and avoid blame. In contested environments, LEOs may initially respond to grassroots contestation by trying to deflect responsibility by specifying an alternate government as the locus of authority on the issue (Proposition 2.2). When this strategy succeeds, we expect negative policy action, and when it fails, we expect LEOs' approaches to HVHF to vary in line with the degree of contestation to which they are exposed.

When contestation occurs over a limited period and is less intense, LEOs may take actions that acknowledge HVHF without addressing it. For example, resolutions allow LEOs to appear active on the issue of HVHF without committing to policy actions that could materially impact battling local interests. Resolutions are the only policy type adopted by New York LEOs that could have no direct impact on if and how HVHF would actually occur. Resolutions were purely symbolic actions that communicated a municipality's position on HVHF or aspects of relevant policy. For example, a resolution adopted by the Town of Delaware states:

Be it hereby resolved, that any landowner or entity that owns the rights to minerals within the corporate bounds of the Town of Delaware has the right to determine how they exercise and protect their mineral rights in accordance to the laws of the State of New York and to the laws of the United States of America. 
This resolution indicates that New York State is the ultimate decision-making authority on HVHF - while still being a policy action for which LEOs can take credit. In this regard, Edelman's concept of symbolic policy is instructive (Edelman 1960, 1964, 1971). Symbolic policies are those which communicate support for a policy position without substantively impacting policymaking. Symbolic policies may reduce public pressures for action simply by offering the impression that the issue is being dealt with (Lubell 2004a, b). Resolutions on HVHF adopted by New York municipalities fit this mold. They do not halt or reduce HVHF activity within the jurisdiction, nor do they impose penalties on the industry for any negative impacts that HVHF may generate. However, they can be leveraged to express a position on HVHF which aligns with the preferences of grassroots stakeholders. Thus, LEOs operating in low-contestation policymaking environments will adopt more symbolic policies than substantive policies (Proposition 2.3).

When contestation is high, the pressure for LEOs to take action on HVHF is sustained even as decisional complexity rises. When stakeholder engagement is highly contested, the amount of information being shared about HVHF increases as competing constituencies deliberate over policy issues and alternatives. Each additional piece of information pressed on LEOs increases the complexity of addressing HVHF (Brugnach et al. 2011; Weiss 1982). In this situation, rather than design and deploy a single policy to address the issue, LEOs may decompose HVHF into smaller subparts which can be treated as more familiar decision-making scenarios. As Mintzberg et al. $(1976,247)$ theorize, "the decision makers deal with unstructured situations by factoring them into familiar, structural elements." In other words, the sustained difficulty of addressing HVHF discourages LEOs from directly and comprehensively confronting the thorny issue, and instead encourages them to break HVHF down to more discreet (and individually less controversial) problems such as inadequate information, noise pollution, or infrastructure damage. We thus expect that HVHF policy making will be more protracted in high-contestation cases compared to low-contestation cases (Proposition 2.4).

\section{Materials and methods}

We use a case study approach to examine in-depth local HVHF policy processes and interactions between LEOs and the public (Hay 2010). The cases were selected based on theoretical and practical criteria. We first considered only those New York municipalities which responded to a survey $(n=481,31 \%$ response rate), administered in Summer 2014, concerning municipal-level HVHF policymaking (see Arnold et al. 2017; Arnold and Nguyen Long 2018). Second, we considered only those municipalities wherein a survey respondent (the municipal clerk) reported that both pro- and anti-HVHF policy interests lobbied ${ }^{4}$ local decision makers. This left 55 eligible municipalities. From those 55, we were able to obtain complete sets of public meeting minutes (2008-2012) for 38 by June 2017. ${ }^{5}$ From these,

\footnotetext{
${ }^{4}$ Grassroots stakeholders lobbied LEOs in different ways. Some signed petitions, while others organized protests or wrote letters to the town board. In this study, we observe direct lobbying through attendance in regularly scheduled municipal meetings and participation in discussions on HVHF in this venue.

5 We have been requesting public meeting minutes from New York municipalities since 2015. A number of municipalities have taken years to respond to these requests, while others have not responded at all despite multiple requests and appeals. Public record requests of this nature can be burdensome, particularly when records are not digitized and must be copied by a clerk who works limited hours and has multiple job responsibilities.
} 
we identified for focused study 13 municipalities that were similar along multiple dimensions relevant to HVHF policymaking.

Specifically, we reduced the sample from 38 to 13 by excluding from study those municipalities with values more than one standard deviation below or above the mean (for the group of 38) on Democratic partisanship (the percentage of citizens voting for President Barack Obama in 2008), then on population density, and finally on residents' logged per capita income in 2000. Multiple studies have found that New York municipalities with more Democratic partisans are more likely to adopt anti-HVHF measures, while less dense (i.e., more rural) and poorer municipalities are less likely to do so (see Arnold and Nguyen Long 2018; Arnold et al. 2017; Barnes 2013; Dokshin 2016; Walsh et al. 2015; Zirogiannis et al. 2015). By ensuring that the 13 municipalities left in the sample are relatively similar along these dimensions, we hold the dimensions more or less constant. This implies that if LEO policymaking on HVHF varies, this variation is less likely to derive from differences in contextual variables and more likely to flow from other factors, such as the nature of stakeholder engagement.

We obtained public records of municipal meeting minutes by manually downloading them from municipality websites, where available, and obtaining them with Freedom of Information Law requests to municipalities where they were not. A Python script applied to the entire corpus of meeting minutes was used to identify, on the basis of $13 \mathrm{HVHF}$ related key words, ${ }^{6} 216$ public meetings where HVHF was discussed.

Two research team members developed and used a codebook (see Appendix) to analyze the meeting minutes. Codes identified people speaking on HVHF at the public meetings, a speaker's stance regarding HVHF, and, when relevant, the type of action being discussed at the meeting, be it a request for action by a grassroots stakeholder or a consideration of action by an LEO. The coded minutes were then crosschecked and reconciled by the two researchers.

Each HVHF-relevant statement made during a public meeting was coded, using definitions rooted in the literature on public policy decision making. Deflecting strategies were identified when an LEO said that the responsibility for regulating HVHF belonged to an authority other than themselves, or when an LEO used another authority (town, state, or agency) as a reason to not take an action or to delay an action on HVHF. We treat all resolutions as symbolic policy actions. Adoption of road use agreements, bans, or moratoriums constituted a substantive action.

We have four types of cases. First are cases with no grassroots stakeholder engagement (two cases). Second are uncontested cases with grassroots stakeholder engagement fully on one side of the issue. Stakeholders were assigned codes on the basis of their stated attitudes (positive/welcoming versus concerned) toward HVHF (see Codebook 1 in Appendix). When both pro- and anti-fracking stakeholders contemporaneously place opposing demands on LEOs, we considered these cases to be contested. We then broke contestation down by year in the six contested cases. This allowed us to categorize the contested cases into low and high contestation, where high contestation is marked by longer duration of engagement ${ }^{7}$ and/or greater levels of engagement by the public.

\footnotetext{
${ }^{6}$ The 13 search terms were: hydrofracking, hydraulic fracturing, hydraulic fracking, fracking, fracing, shale gas drilling, shale drilling, shale gas, shale, natural gas drilling, Marcellus Shale, gas drilling, and Utica Shale.

${ }^{7}$ Roughly three years or more; the average duration in contested cases was 2.67 years.
} 
Table 1 Number of times grassroots stakeholders discussed HVHF at a public meeting

\begin{tabular}{llllrlrrl}
\hline & Candor & Bainbridge & Triangle & Hector & Otego & Delaware & Mean & Min-Max \\
\hline 2008 & 0 & 0 & 0 & 0 & 0 & 5 & 0.83 & $0-5$ \\
2009 & 0 & 0 & 0 & 17 & 0 & 1 & 3.00 & $0-17$ \\
2010 & 3 & 3 & 3 & 1 & 0 & 9 & 3.17 & $0-9$ \\
2011 & 1 & 0 & 0 & 60 & 6 & 5 & 12.00 & $0-60$ \\
2012 & 0 & 0 & 12 & 127 & 60 & 5 & 34.00 & $0-127$ \\
$\begin{array}{l}\text { Study } \\
\text { period } \\
\text { totals }\end{array}$ & 4 & 3 & 15 & 205 & 66 & 25 & 53.00 & $3-205$ \\
\hline
\end{tabular}

This counts engagement by both pro- and anti-HVHF grassroots stakeholders

Engagement encompasses a wide range of behaviors, from attending rallies to deliberating at public meetings to organizing community action. We focus here on the type of engagement that is specific to public meetings: deliberating. We measure level of engagement by counting the number of times grassroots stakeholders address LEOs on the topic of HVHF at public meetings in each study year (see Table 1). From 2008 to 2012, grassroots stakeholders addressed their town board on this topic as few as three times (in Bainbridge) and as many as 205 times (in Hector). Grassroots stakeholder participation tends to intensify in 2011 and 2012. With the exception of Hector, most municipalities see fewer than ten incidences of grassroots stakeholder engagement until 2011. Thus, we consider cases where engagement in any year is higher than 10 to be a high-engagement case and those with lower than 10 as low-engagement cases.

The policy outcomes for each municipality (i.e., whether they adopted HVHF policies, what kind, and how many) were determined by consulting an original database of HVHF policies the research team assembled by consulting FracTracker, Food and Water Watch, Keuka Citizens Against Hydrofracking, and the Joint Landowners Coalition of New York. Every 3-6 months, the team checked for updates to these sources, supplementing with Internet searches for news articles documenting local fracking policy passage. We also searched the New York State Public Law Database (NYSPLD) for HVHF-related keywords to identify measures missed by the other sources. When at least two non-NYSPLD ${ }^{8}$ sources documented passage of a policy, we generally considered it verified. If only one indicated passage, we sought clarification via public information requests to the municipality and/or consulting NYSPLD. Finally, we verified timing of policy adoption via public information requests, municipal public meeting minutes, and NYSPLD. Figure 1 demonstrates the variety of HVHF policy adoption among the 13 cases. The municipalities differ in the number of HVHF policies adopted, from zero to four.

\footnotetext{
${ }^{8}$ We considered NYSPLD-archived measures verified even if only listed there. However, NYSPLD was not used as the sole source because resolutions are not archived, municipalities sometimes fail to file laws, and NYSPLD searches are not considered official queries and the state does not guarantee database accuracy.
} 


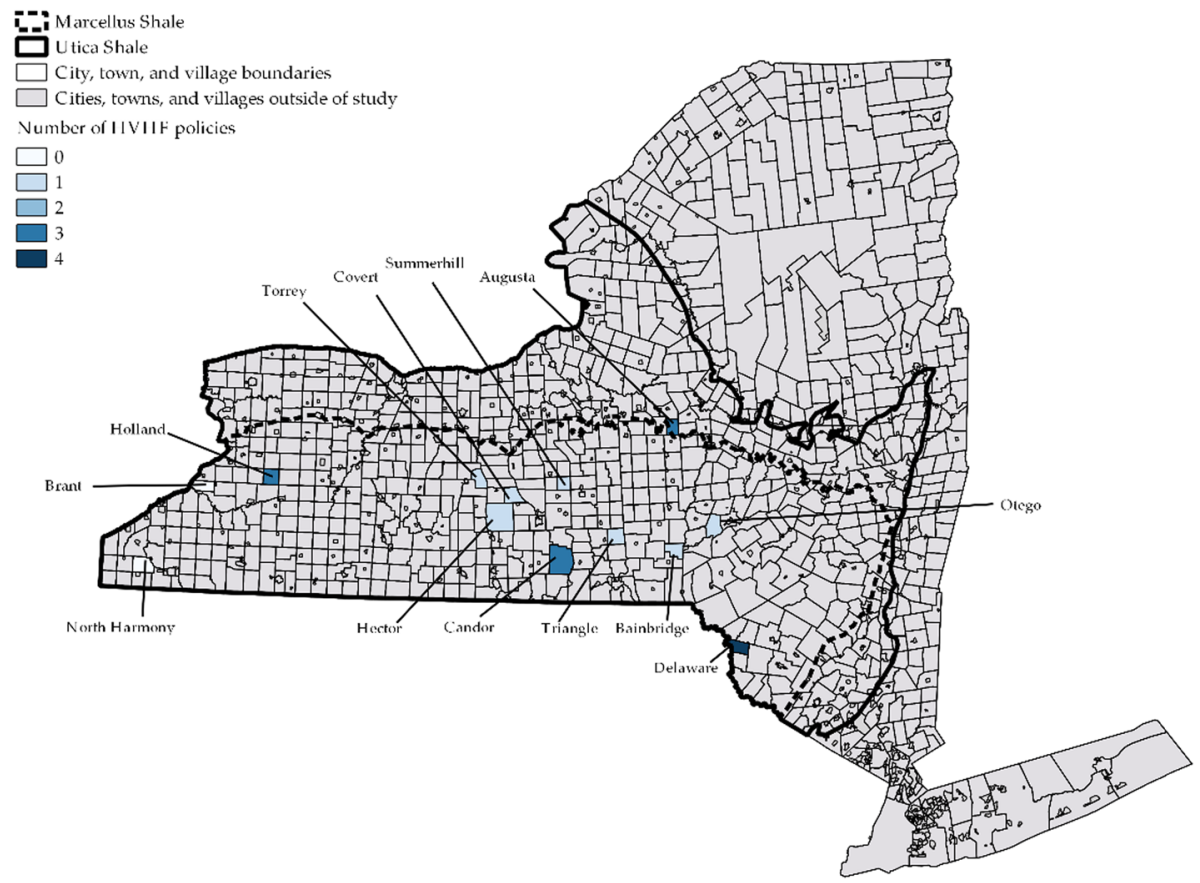

Fig. 1 Case study municipalities and number of policies adopted

\section{Findings}

The level of public engagement on HVHF varied greatly across municipalities (see Table 1). Two towns, Brant and North Harmony, had no evidence of stakeholder engagement on the issue. Stakeholder engagement was uncontested in Augusta, Covert, Holland, Summerhill, and Torrey. In the six remaining towns it was contested, with contestation low in Bainbridge, Candor, and Triangle and high in Delaware, Hector, and Otego.

The bar charts in Fig. 2 break contestation down by year for each of the six cases with contestation. In all cases, engagement by anti-HVHF stakeholders (dark gray bars) was greater than engagement by pro-HVHF stakeholders (light gray bars).

In the three low-contestation cases, engagement began (and in the case of Bainbridge ended) in 2010. The presence of opposing stakeholder views was very weak in Bainbridge, where stakeholder registered these opinions at public meetings for only 1 year (2010) and discussed HVHF with LEOs fewer than five times that year. In Candor and Triangle, we detected contestation in 2 years; pro- and anti-HVHF stakeholders spoke on HVHF fewer than ten times for each of those years.

Contestation was relatively stronger in Delaware, Hector, and Otego. Otego is considered a high-contestation case because, although contestation lasted only 2 years, the frequency with which stakeholders spoke on HVHF at these public meetings intensified quickly, more than tripling over that period. In Delaware and Hector, engagement stretched out for a longer period, with Delaware showing a fairly even pattern 
Low Contestation
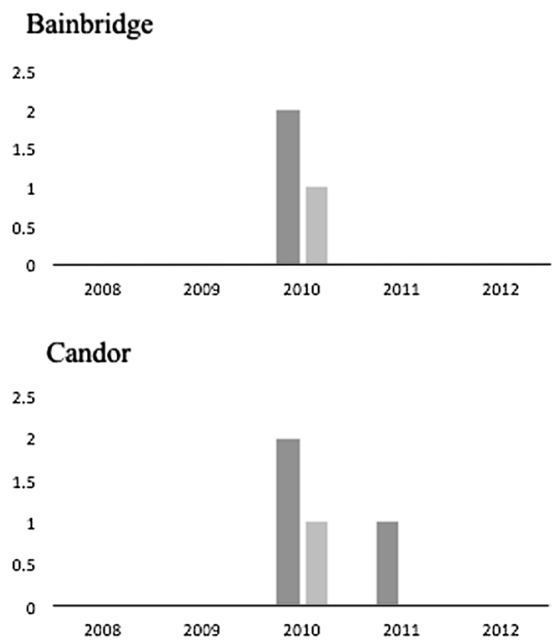

Triangle

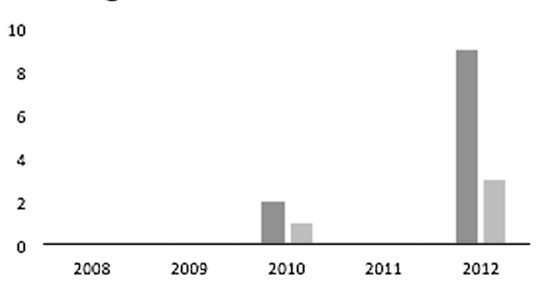

High Contestation
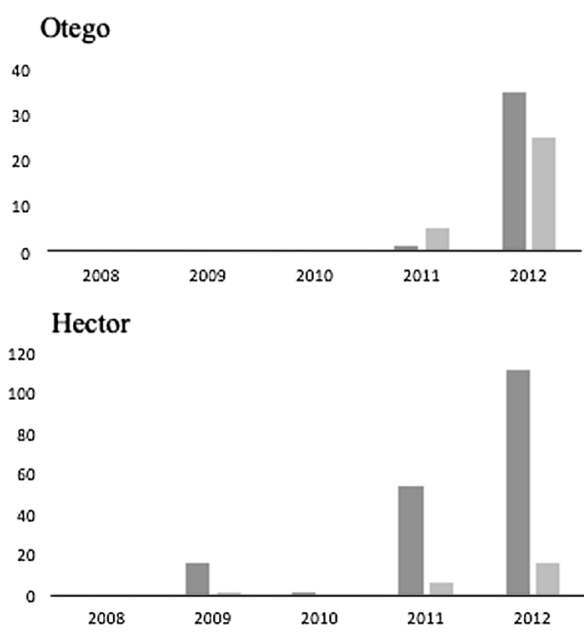

Delaware

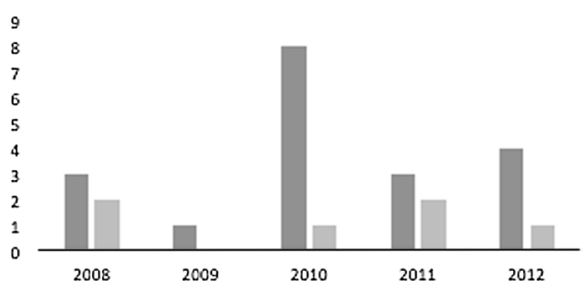

Fig. 2 Breakdown of stakeholder engagement for each case, for each year. Note In the bar charts in Fig. 2, the $x$-axis values are the years, and the $y$-axis values are the number of times that grassroots stakeholders addressed the board at a public meeting that year. Dark gray bars represent a count of the number of times an anti-HVHF grassroots stakeholder addressed the board. Light gray bars represent a count of the number of times a pro-HVHF grassroots stakeholder addressed the board

of participation, with a peak in 2010, and Hector showing a pattern of intensifying contestation.

Hector experienced the most intense conflict, in terms of the duration and frequency of engagement by opposing grassroots stakeholders in public meetings. The case of Hector illustrates how contentious HVHF can become and how resulting conflicts can affect LEO behaviors. Here, an LEO acknowledged that the, "past election's biggest issue was fracking or no fracking, [I] do not like that this line has been drawn, the town is split" (February 14, 2012; Town of Hector board meeting). Contestation at public meetings over HVHF intensified over time. At one point, a sheriff's deputy was called to maintain order. When questioned about why the deputy was at the meeting, the town supervisor responded, "There are concerns with some people being uncomfortable; i.e., a knife thrown across the table a couple months ago." At the next month's town board meeting, the supervisor instructed the public to learn about the rules and norms governing town board meetings by visiting the NY Association of Town's website and 
Table 2 Public participation and interaction in municipal meetings

(a) Uncontested public engagement

\begin{tabular}{|c|c|c|c|c|}
\hline & & \multicolumn{2}{|c|}{ Meetings with public engagement } & \multirow{2}{*}{$\begin{array}{l}\begin{array}{l}\text { Requests } \\
\text { for action }\end{array} \\
15\end{array}$} \\
\hline Augusta & & \multicolumn{2}{|l|}{18 public meetings } & \\
\hline Covert & & \multicolumn{2}{|l|}{7 public meetings } & 16 \\
\hline Holland & & \multicolumn{2}{|l|}{10 public meetings } & 8 \\
\hline Summerhill & & \multicolumn{2}{|l|}{19 public meetings } & 9 \\
\hline Torrey & & \multicolumn{2}{|l|}{18 public meetings } & 23 \\
\hline \multicolumn{5}{|c|}{ (b) Contested public engagement } \\
\hline & $\begin{array}{l}\text { Meetings with public } \\
\text { engagement }\end{array}$ & $\begin{array}{l}\text { Requests for action made by } \\
\text { pro-HVHF stakeholders }\end{array}$ & \multicolumn{2}{|c|}{$\begin{array}{l}\text { Requests for action made } \\
\text { by anti-HVHF stakeholders }\end{array}$} \\
\hline \multicolumn{5}{|c|}{ Low-contestation cases } \\
\hline Bainbridge & 10 public meetings & 1 & \multicolumn{2}{|c|}{6} \\
\hline Candor & 12 public meetings & 1 & \multicolumn{2}{|c|}{3} \\
\hline Triangle & 21 public meetings & 5 & \multicolumn{2}{|c|}{7} \\
\hline \multicolumn{5}{|c|}{ High-contestation cases } \\
\hline Delaware & 35 public meetings & 8 & \multicolumn{2}{|c|}{15} \\
\hline Hector & 40 public meetings & 21 & \multicolumn{2}{|c|}{189} \\
\hline Otego & 14 public meetings & 31 & \multicolumn{2}{|c|}{35} \\
\hline
\end{tabular}

We exclude Brant Town (three public meetings) and North Harmony Town (nine public meetings) because we do not detect stakeholder interventions at these meetings, ergo there was no claims making to document

reviewing local laws and procedures for town meetings (Town of Hector board meeting, April 10, 2012).

\section{The quantity and quality of grassroots stakeholder engagement varied across cases}

Grassroots stakeholders provided municipal board members information about HVHF, provided opinions on different HVHF policy types, and tried to build consensus around different policy actions. They presented LEOs with petitions, tried to connect LEOs with outside experts on HVHF, wrote letters to LEOs, and offered to provide HVHF resources-such as expertise and/or time-to municipal government. Grassroots stakeholders sometimes requested that LEOs take action on HVHF; see Table 1. All things held equal, the greater the number of requests for action by stakeholders, the higher the pressure LEOs feel to address HVHF. Notice that the requests for action in the low-contestation cases are noticeably less frequent compared to the requests for action made in the high-contestation cases (Table 2).

Many of the observations yielded by our content analyses of the cases support our propositions about LEO action, while some nuance or contradict them. The italicized statements below are the main "take-aways" from the analysis. 
Table 3 LEO responses to public engagement in municipal meetings

\begin{tabular}{lll}
\hline & Period & Type of policy adopted \\
\hline $\begin{array}{l}\text { No stakeholder engagement } \\
\text { Brant }\end{array}$ & $2010-2011$ & N/A \\
North Harmony & $2010-2012$ & N/A \\
Uncontested stakeholder engagement & & \\
$\begin{array}{l}\text { Augusta } \\
\text { Covert }\end{array}$ & $2010-2012$ & 3 Moratoriums \\
Holland & $2011-2012$ & Resolution \\
& $2010-2012$ & 2 Resolutions \\
Summerhill & & Ban \\
Torrey & $2008-2012$ & Ban \\
& $2009-2012$ & Moratorium \\
$\begin{array}{l}\text { Contested stakeholder engagement (low contestation) } \\
\text { Bainbridge }\end{array}$ & & Ban \\
Candor & $2008-2012$ & Resolution \\
Triangle & $2008-2012$ & 2 Resolutions \\
Contested stakeholder engagement (high contestation) & & Road Use Law \\
$\begin{array}{l}\text { Delaware } \\
\text { Hector } \\
\text { Otego }\end{array}$ & $2008-2012$ & Road Use Law \\
\hline
\end{tabular}

\section{When there is no stakeholder engagement, LEOs opt for a "status quo" response to HVHF}

Our observations support Proposition 1. There was no stakeholder engagement in Brant and North Harmony. In Fig. 1, North Harmony and Brant are in the lower left-hand corner of the map, and both adopted no policies on HVHF. LEOs in both towns behaved as predicted by status quo proclivity, taking no policy action and leaving HVHF policymaking in the hands of the state. In Brant, LEOs argued that, "what actions the state takes as legislation would not fall under town law" (Town of Brant board meeting, December 14, 2010). In North Harmony, LEOs argued that, "this type of drilling is not being done in our area." (Town of North Harmony supervisor, at a board meeting, May 14, 2012). In both towns, LEOs largely sought to inform themselves about HVHF and how the state intended to regulate it, for example, by attending informational sessions. LEO engagement level is notably lower than in cases in where stakeholders engaged on the issue.

\section{When public engagement is uncontested, LEOs take substantive, anti-HVHF actions prohibiting HVHF}

Proposition 2.1 expects LEOs who face uncontested publics to be responsive to their demands, particularly those for substantive actions. Our content analysis reveals behaviors partially supporting these expectations. Substantive actions are not the exclusive 
provenance of municipalities without contested publics; LEOs in municipalities with both contested and uncontested engagement took substantive actions. However, we do find a difference in the types of substantive actions municipalities take: LEOs who face contested engagement and take substantive action exclusively adopted road use policies, while those that faced uncontested engagement adopted the more HVHF-prohibitive bans and moratoriums. It appears that when LEOs experiencing contestation take substantive action, they gravitate toward the middle-impact, arguably compromise approach to HVHF embodied in road use measures, seeking to condition but not stop industry activity.

Grassroots stakeholder engagement was uncontested five cases: Augusta, Covert, Holland, Summerhill, and Torrey. Of these five, only Covert did not adopt a substantive policy. The remaining four adopted at least one policy that prohibited HVHF within the jurisdiction (see Table 3).

Augusta LEOs adopted three moratoriums on HVHF: an initial moratorium in 2011 and two extensions in 2012. Meeting minutes show that Augusta LEOs were very responsive to stakeholder engagement. On July 20, 2011, a month after being presented with a draft moratorium and a petition signed by 300 residents (Town of Augusta board meeting, June 15, 2011), Augusta LEOs set in motion a series of actions that led to a first moratorium being adopted in October 2011. Similarly, when challenged to "enact laws to protect the town from the threat of HVHF" (Town of Torrey board meeting, May 19, 2011), Torrey LEOs drafted a 1-year moratorium. Adopted on February 14, 2012, the moratorium aimed "to prevent serious detrimental health and environmental effects posed by the practices of horizontal or directional gas drilling and hydraulic fracturing" (Town of Torrey board meeting, November 7, 2011). Later, Torrey LEOs responded to requests for a ban by forming a committee to study HVHF policy options and then revising the municipal zoning code to "prohibit mining," hoping to address HVHF permanently.

Summerhill LEOs also took substantive action, banning HVHF in 2012. In September 2010, LEOs received a letter from residents expressing concerns about HVHF. The first incident of direct engagement in Summerhill happened the following spring, when an antiHVHF advocate requested a ban on HVHF at a public meeting (Town of Summerhill board meeting, March 8, 2011). The same individual repeated these demands at meetings in July and August 2011. In September 2011, Summerhill LEOs scheduled a public hearing on the ban ultimately adopted in 2012 .

What happened in Holland suggests that pressure from uncontested publics can encourage LEOs to change their positions on issues like HVHF. Holland LEOs adopted a proHVHF resolution in 2010, asking the state legislature to "stand aside regarding the issue of drilling in the Marcellus and allow the DEC to complete the sGEIS and issue permits for horizontal drilling" (Resolution \#64, Town of Holland board meeting, August 11, 2010). But in response to citizens expressing anti-HVHF sentiment at a board meeting in March 2011, Holland LEOs reversed their position and passed an oppositional resolution. Holland LEOs eventually banned HVHF in 2012, again in response to a request from the public.

The Town of Covert is the only municipality in our sample where uncontested public engagement did not contribute to substantive policy action. HVHF was addressed at seven meetings of the Covert Town Board occurring between October 2011 and December 2012. Concerns about HVHF were raised by members of a group called Concerned Citizens of Covert. They asked Covert LEOs to "organize a petition to understand where [the] town stands on HVHF" (Town of Covert board meeting, July 9, 2012). Covert LEOs did survey residents about HVHF, but stated that they were "not convinced about the accuracy of surveys" (Town of Covert board meeting, September 10, 2012). This case implies that 
advocacy from uncontested stakeholders may result in substantive action only when stakeholders articulate specific, substantive requests for action.

\section{LEOs defer to the state when facing contested stakeholder engagement}

Observations from the content analyses align with Propositions 2.2, which expects LEOs in municipalities where stakeholder engagement is contested will try to deflect responsibility for HVHF policymaking. We observe such actions in our cases with grassroots stakeholder contestation, irrespective of whether contestation is high or low. In Delaware, a high-contestation case, LEOs adopted a resolution in 2010 which placed responsibility for regulating the negative impacts of HVHF on the state Department of Environmental Conservation. This resolution asked the New York State Legislature, "to compel DEC to protect the citizens of the state of New York without impinging on property rights." (Town of Delaware board meeting, April 21, 2010). Bainbridge, the lowest contestation case, adopted a resolution acknowledging, "the State Department of Conservation as the lead agency in the safe development of natural gas" (emphasis added). When passing resolutions, LEOs in jurisdictions with contestation often used their time on the council floor to deflect responsibility for fracking. In one exchange in Hector, LEO Alvin White claims, "I believe the State has taken the authority; read the law; until court case is settled I'm not going to put the town under that type of liability." To which his colleague LEO Marie Stevens adds, "I took an oath to obey the laws of the State of New York; I'm not going to break the law; if it is as clear cut as you would like to say it is, the judge would have already made a decision; I'm assuming since he has not, that it is not as clear cut as you might think or believe" (Town of Hector board meeting, February 14, 2012).

\section{When public engagement is slightly contested, LEOs seem to adopt more symbolic than substantive actions, but not at a rate notably higher compared to highly contested grassroots engagement}

Our sample includes three low-contestation cases: Bainbridge, Candor, and Triangle. Of the three, the municipality with the lowest level of contestation was Bainbridge, where grassroots stakeholder engagement was both brief and infrequent. The municipality with the most intense contestation was Triangle.

In line with our proposition, the Town of Bainbridge adopted a pro-HVHF resolution on July 10, 2012. In contrast, in Candor, the Town changed supervisors during the study period and there was also some turnover in the membership of the town board. The low intensity of contestation gave Town LEOs some political slack and even permitted them to explicitly go against preferences of some stakeholders, adopting a pro-HVHF measure rather than an HVHF prohibition which some had sought. Indeed, the board passed a profracking resolution and the supervisor read from the resolution, for the record, that, "pursuit of a ban or moratorium to be an irresponsible and premature misallocation of town resources pending release of the SGEIS." (Candor Town board meeting, July 10, 2012).

The Town of Triangle took nine policy actions over a 5-year period. One of these actions established a study HVHF committee, where member LEOs tackled different aspects of HVHF (e.g., the supervisor investigated legal aspects, another council member addressed road use and maintenance) (Triangle Town board meeting, September 9, 2012). This case is notable in Triangle also adopted a (substantive) road use agreement in 2009. The issue of HVHF's impacts on roads was first introduced by a Triangle LEO who, as an interested 
property owner, attended a gas lease informational meeting. At that meeting, he learned about land-use ordinances that would require industry to bond for road maintenance and repair (Triangle Town Board Meeting July 2008); this propelled him to encourage Triangle to adopt such a law. This instance suggests that, when LEOs are able to gain greater knowledge about HVHF, whether through collective learning (e.g., HVHF study committee) or individual (the LEO landowner seeking gas lease information), they may feel more confident in adopting a substantive policy.

Proposition 2.3 expects that LEOs facing low stakeholder contestation will prefer less risky symbolic actions over substantive ones. We do detect this pattern in Bainbridge. However, Candor and Triangle also adopt substantive road use policies during the study period (Table 2). Therefore, our observations do not provide support for Proposition 2.3.

\section{When public engagement is highly contested, LEOs decision-making processes will be more protracted compared to low-contestation cases}

Proposition 2.4 expects that LEOs facing contestation tackle HVHF in a more attenuated manner, often iteratively tackling different dimensions of the issue (e.g., road use) in a piecemeal fashion rather than wholesale. Table $2 \mathrm{~b}$ reflects the pressures which would encourage such an approach, showing that LEOs in municipalities where HVHF was highly contested fielded substantially more requests for different types HVHF-relevant action than their counterparts facing low contestation. It also shows that their consideration of HVHF tended to last longer, lasting up to 40 public meetings in the case of Hector. In what follows, we describe how decision making unfolded in the high-contestation cases.

Otego Town's LEOs sought to adopt a moratorium but delayed taking a decision because of uncertainty regarding the town board's jurisdiction over HVHF. In one instance, the board postponed a vote on the moratorium after a member of the public "gave board a copy of paperwork concerning the court case in Binghamton as a result of their passage of a moratorium law" (Town of Otego board meeting; October 1, 2012). A month later, the town's lawyer presented a revised version of the moratorium, stating "There was a challenge to a similar law in Binghamton because the law was establishing the moratorium under police powers rather than land use." A discussion followed about having a public hearing on the revised law "to avoid legal challenge" (Town of Otego board meeting, November 13, 2012). Otego eventually adopted a moratorium in 2013 (outside the study period). Facing decisional complexity, the board took a series of discrete actions, such as surveying the town residents on their attitudes toward HVHF, seeking the assistance of legal and engineering experts, and preparing and presenting draft laws at public hearings, as a path toward building certainty and momentum necessary for substantive policy action.

Delaware LEOs also addressed HVHF repeatedly, using discrete and familiar actions. HVHF's high local salience, signaled by high levels of contestation, encouraged officials to take action to demonstrate their responsiveness to voters. Delaware LEOs decided to adopt a road use policy but found themselves lacking the resources, preparation, or experience to swiftly enact such a policy. Thus, they pooled resources with neighbors in the county, tackling HVHF's potential road impacts by joining a multi-municipality task force focused on this issue. Their engagement in the task force involved familiar tasks such as engaging in a property assessment study (Town of Delaware board meeting; June 7, 2009). In the end, Delaware LEOs did not adopt a road use agreement, but did adopt four resolutions (an arguably more familiar activity) addressing discrete dimensions of HVHF, such 
as supporting home-rule authority over HVHF-related issues and supporting the rights of landowners to make decisions about drilling on their property.

Similarly, Hector's LEOs responded to decisional complexity and issue salience with a long sequence of policy actions. Hector adopted a road use law in 2012, but efforts to secure it began in 2009. Hector LEOs repeatedly attempted to modify the law to make it more palatable all stakeholders, despite their disagreements (see Mintzberg et al. 1976). For example, at one point the Hector LEOs tried to couple some stakeholders' demands for a moratorium with LEO preference for a road use law (Hector Town board meeting, December 29, 2011). After numerous revisions, hearings, and discussions, LEOs finally adopted the road use measure- a middle-of-the-road action not purely symbolic like a resolution but not as prohibitive as a ban or moratorium — arguably as a compromise among diverse stakeholder interests.

\section{Discussion and conclusions}

In this paper, we offer a nuanced account of patterns that arise when publics engage with local elected officials. While some herald public engagement in policymaking as a positive development, increasing the legitimacy of public policy and potentially resulting in more targeted and innovative solutions (Bingham et al. 2005; Fung 2006), others argue that engagement minimally impacts decision making and at best serves as a buffer for elected officials seeking to deflect criticism about process legitimacy (Rowe and Frewer 2000; Kemp 1985). Greater citizen engagement with elected officials may not only fail to promote substantive policy change, but also dampen advocacy as symbolic policy actions satiate grassroots stakeholder demands (Lubell 2004a). While work in this vein emphasizes the importance of institutional design for getting grassroots stakeholders to participate in meaningful ways (Few et al. 2007; Fung 2006; Irvin and Stansbury 2004), it provides little insight into the role of leadership in shaping participation processes and outcomes (Fung 2015). What is more, whereas some scholars emphasize the deleterious impact that conflict may have on public deliberative processes, in practice this literature largely treats the public as a single homogenous entity (see Few et al. 2007; Reed 2008). By focusing on how contested and uncontested grassroots stakeholders impact LEO decision making, we begin to tease apart the patterned behaviors which give rise to different policy outcomes. Thus, we are able to reconcile accounts of futile stakeholder engagement (e.g., Few et al. 2007) with successful stakeholder engagement (e.g., Bingham et al. 2005) by showing what works when, and why.

Our content analysis of public documents captures local-level efforts to respond to the policy and political challenges created by HVHF. The analysis frequently supports our propositions regarding the impact that public engagement has on local HVHF governance. This engagement shapes political discourse around the issue and increases the likelihood of policymaking about it, albeit not necessarily encouraging substantive action. Uncontested publics appear to hold more sway over the policy outcomes than contested publics. However, contested publics still are able to affect the political behavior of LEOs, pushing them to defend their political stances and offer policy action as evidence of responsiveness. In some cases, like the Town of Otego, smaller, discrete policy actions tackling dimensions of HVHF may pave the way for more substantive action later (although we do not explore such temporal dynamics in detail here). 
We are also able to provide support for Daviter's (2015) hypothesis that novel policy processes are an opportunity for jurisdictions to widen or restrict their authority over an issue. This finding holds significant implications for current studies of multi-level governance, where scholars are trying to unpack questions over how conflict and redundancy may be avoided (or used constructively) when rule-making takes place in overlapping jurisdictions (Andersson and Ostrom 2008, for example).

This study does, however, have limitations. It does not consider how specific characteristics of LEOs, such as political partisanship, occupation, and experience in office, may affect their decision making. There is a large literature on how factors such as these affect officials' incentives and capacities (e.g., Zhang and Feiock 2010; Teodoro 2011). For example, LEOs in less contested cases may share policy beliefs with their constituents and LEOs in contested cases may vary in their beliefs. To wit: In the Town of Triangle, the LEO who championed the Town's adoption of a road use policy was personally interested in HVHF because he wanted to lease his land to the natural gas industry. LEO characteristics may indeed influence their decision making, but investigating those dynamics lies outside the scope of this current study. Our study assumed that LEO characteristics are roughly randomly distributed across municipalities, such that they would not systematically affect LEO behavioral patterns identified in our sample of 13 jurisdictions. In the future, this assumption should be quantitatively tested across a larger number of cases and qualitatively evaluated through interviews. Finally, this paper only considers interactions between grassroots stakeholders and LEOs, ignoring other actors, e.g., industry or civil society. Future work can delve into how navigating these dynamics impacts LEO behaviors.

The findings provide ample motivation for deepening study. A large- $\mathrm{N}$ analysis could be conducted with a simplified codebook and automated text analysis. Such a study could not only indicate how generalizable our findings are, but a larger data set with more variability in contestation levels could also reveal other linkages between policy outcomes and the interplay between LEO and grassroots stakeholder behaviors. Policymaking is made by collectives and the purposive and strategic actions of individuals embedded within these collectives. Therefore, studies of collective political behavior need to be complemented by studies like ours, investigating how individual agents navigate the policy process. Our analysis suggests that individuals in leadership positions can critically impact the direction of environmental policy. One obvious example is the leadership in this area by the Obama administration and its reversal by the Trump administration. Such shifts in policy are occurring across all levels of government. Understanding patterned behaviors of actors who are endowed through the democratic process with decision-making authority is critical to fully understand how local governments may navigate challenging environmental policymaking, and in the process potentially influence outcomes at other levels of governance.

Acknowledgements This work was supported by the National Science Foundation's Decision, Risk, and Management Sciences Program (NSF SES-1535004).

Open Access This article is distributed under the terms of the Creative Commons Attribution 4.0 International License (http://creativecommons.org/licenses/by/4.0/), which permits unrestricted use, distribution, and reproduction in any medium, provided you give appropriate credit to the original author(s) and the source, provide a link to the Creative Commons license, and indicate if changes were made. 


\section{Appendix A: HVHF case study codebook}

\section{HVHF case study codebook}

\section{Codebook 1: coding for the speakers}

B: board member or actor affiliated with the board (e.g., Highway Superintendent or Planning Board Chair)

Note the board's stance on fracking at the beginning of the spreadsheet. If there is disagreement on stance among board members, then note the board member's stance (Pro $=P$, $A n t i=A, N e u t r a l=N)$ in parenthesis next to the code (e.g., B_Supervisor/mayor $(P))$. If board changes stance, note changes to board membership and timing of change.

- B_Supervisor

- B_councilmember

- Board (2+ council members)

- B_publicadmin

- B_auxiliary_planningbd

- B_auxiliary_hwysuperintendent

- B_auxiliary_countyrep

- B_auxiliary_atty (town attorney)

- B_auxiliary_cb (conservation board)

- B_auxiliary_other

P: Member of the public and attitude toward fracking

- $\mathrm{P}(\mathrm{P})(\mathrm{Pro})$

- $\mathrm{P}(\mathrm{N})($ Neutral)

- $\mathrm{P}(\mathrm{A})($ Anti)

- $\mathrm{P}(\mathrm{UN})$ (Unsure)

E: Outside expert

- E_engineer(stance)

- E_legal expert(stance)

- E_ scientific expert(stance)

- E_othergovt

\section{Codebook 2: coding for action}

AR: request for an action to be taken

Note when a request for action is made and the policy valence of that action. Note also if the request is explicit (E), for example, "we would like the town to ban fracking," or implicit (I), for example, "the town needs to protect its residents from fracking."

- $\mathrm{AR}(\mathrm{P})$ : Pro-fracking action request

- $\operatorname{AR}(\mathrm{N})$ : Neutral action 
- $\mathrm{AR}(\mathrm{A})$ : Anti-Fracking action request

- AR(Stance)_I

- AR(Stance)_E

AT: Action Taken $($ pro $=\mathrm{P} /$ neutral $=\mathrm{N} / \mathrm{anti}=\mathrm{A})$

- AT_policyproposal(P/N/A)

- AT_vote

- AT_policyadoption

- AT_hearing

- AT_visted nearby town

- AT_tablediscussion

- AT_other

\section{Overall things to look for}

- Contested/Uncontested: In addition to counts, make note of exchanges where there is disagreement on (a) how fracking is defined as a policy issue, (b) how to deal with fracking, (c) the town's responsibility vis-à-vis fracking

- Responsiveness to public: Make a note if, in discussion, LEO implies/claims that they are pursuing a certain action in response to (a) general public demand or (b) a specific person's intervention/engagement

\section{References}

Adams, B. (2004). Public meetings and the democratic process. Public Administration Review, 64(2), 43-54.

Agranoff, R., \& McGuire, M. (2001). Big questions in public network management research. Journal of Public Administration Research and Theory, 11(3), 295-326.

Andersson, K. P., \& Ostrom, E. (2008). Analyzing decentralized resource regimes from a polycentric perspective. Policy Sciences, 41(1), 71-93.

Ansell, C., \& Gash, A. (2008). Collaborative governance in theory and practice. Journal of Public Administration Research and Theory, 18(4), 543-571.

Arnold, G., \& Nguyen Long, L. (2018). Policy expansion in local government environmental policymaking. Public Administration Review. https://doi.org/10.1111/puar.12905.

Arnold, G., Nguyen Long, L., \& Gottlieb, M. (2017). Social networks and policy entrepreneurship: How relationships shape municipal decision making about high volume hydraulic fracturing. Policy Studies Journal, 45(3), 414-441.

Barnes, M. (2013). Policymaking in New York Municipalities: Determinants of Local Actions toward Hydraulic Fracturing. Chicago, IL: Midwest Political Science Association.

Beierle, T. C. (2002). The quality of stakeholder-based decisions. Risk Analysis: An International Journal, 22(4), 739-749.

Beierle, T. C. (2010). Democracy in practice: Public participation in environmental decisions. London: Routledge.

Berardo, R., \& Holm, F. (2018). The participation of core stakeholders in the design of, and challenges to, the US Clean Power Plan. Climate policy, 18(9), 1152-1164. 
Bingham, L. B., Nabatchi, T., \& O’Leary, R. (2005). The new governance: Practices and processes for stakeholder and citizen participation in the work of Government. Public Administration Review, 65(5), 547-558.

Boin, A., \& Hart, P. T. (2003). Public leadership in times of crisis: Mission impossible? Public Administration Review, 63(5), 544-553.

Brugnach, M., Dewulf, A. R. P. J., Henriksen, H. J., \& Van der Keur, P. (2011). More is not always better: Coping with ambiguity in natural resources management. Journal of Environmental Management, 92(1), 78-84.

Daviter, F. (2015). The political use of knowledge in the policy process. Policy Sciences, 48(4), 491-505.

Devas, N., \& Grant, U. (2003). Local government decision-making-citizen participation and local accountability: Some evidence from Kenya and Uganda. Public Administration and Development: The International Journal of Management Research and Practice, 23(4), 307-316.

DeWitt, K. (2012). Group Says Fracking Would Transform the Rural Landscape. Hurting Tourism: North Country Public Radio.

Dodge, J., \& Lee, J. (2015). Framing dynamics and political gridlock. Journal of Environmental Policy \& Planning, 19(1), 14-34.

Dokshin, F. A. (2016). Whose Backyard and What's at issue? Spatial and ideological dynamics of local opposition to fracking in New York State, 2010 to 2013. American Sociological Review, 81(5), 921-948.

Dutzik, T., Benjamin, D., Van Heeke, T., \& Rumpler, J. (2013). Who pays the costs of fracking. Harrisburg, PA: Penn Environment.

Edelman, M. (1960). Symbols and political quiescence. American Political Science Review, 54(3), $695-704$.

Edelman, M. (1964). The symbolic uses of politics. Urbana: University of Illinois Press.

Edelman, M. (1971). Politics as symbolic action: Mass arousal and quiescence. New York: Academic Press.

Emerson, K., Nabatchi, T., \& Balogh, S. (2012). An integrative framework for collaborative governance. Journal of Public Administration Research and Theory, 22(1), 1-29.

Engelder, T. (2011). Should fracking stop? No, it's too valuable. Nature, 477, 271-275.

Felstiner, W. L. F., Abel, R. L., \& Sarat, A. (1980). The emergence and transformation of disputes: Naming, blaming claiming. Law \& Society Review, 15(3/4), Special Issue on Dispute Processing and Civil Litigation, 631-654.

Few, R., Brown, K., \& Tompkins, E. L. (2007). Public participation and climate change adaptation: Avoiding the illusion of inclusion. Climate Policy, 7(1), 46-59.

Fischer, F. (2000). Citizens, experts, and the environment: The politics of local knowledge. Durham: Duke University Press.

Freeman, R. E. (1984). Strategic management: A stakeholder approach. New York: Cambridge University Press.

Fung, A. (2006). Varieties of participation in complex governance. Public Administration Review, $66(\mathrm{~s} 1), 66-75$.

Fung, A. (2015). Putting the public back into Governance: The challenges of citizen participation and its future. Public Administration Review, 75(4), 513-522.

Gormley, W. T., Jr. (1986). Regulatory issue networks in a federal system. Polity, 18(4), 595-620.

Grimble, R., \& Wellard, K. (1997). Stakeholder methodologies in natural resource management: A review of concepts, contexts, experiences and opportunities. Agricultural Systems, 55, 173-193.

Hay, I. (2010). Qualitative research methods in human geography. Canada: Oxford University Press.

Hood, C. (2002). The risk game and the blame game. Government and Opposition, 37(1), 15-37.

Hood, C. (2007). What happens when transparency meets blame avoidance? Public Management Review, 9(2), 191-210.

Hood, C. (2011). The blame game: Spin, bureaucracy, and self-preservation in government. Princeton, NJ: Princeton University Press.

Howarth, R. W., Santoro, R., \& Ingraffea, A. (2011). Methane and the greenhouse-gas footprint of natural gas from shale formations. Climatic Changes, 106(4), 679-690.

Howlett, M. (2012). The lessons of failure: Learning and blame avoidance in public policymaking. International Political Science Review, 33(5), 539-555.

Howlett, M. (2014a). Why are policy innovations rare and so often negative? Blame avoidance and problem denial in climate change policy-making. Global Environmental Change, 29, 395-403.

Howlett, M. (2014b). From the 'old' to the 'new' policy design: Design thinking beyond markets and collaborative governance. Policy Sciences, 47(3), 187-207.

Howlett, M. (2017). Public Participation in the Policy Process: A Critical Review of Procedural Policy Instruments. Encyclopaedia of Environmental Law. 
Irvin, R. A., \& Stansbury, J. (2004). Citizen participation in decision making: Is it worth the effort? Public Administration Review, 64(1), 55-65.

Jackson, R. B., Vengosh, A., Carey, J. W., Davies, R. J., Darrah, T. H., O’Sullivan, F., et al. (2014). The environmental costs and benefits of fracking. Annual Review of Environment and Resources, 39, $327-362$.

Jacquet, J. B. (2015). The rise of "private participation" in the planning of energy projects in the rural United States. Society \& Natural Resources, 28(3), 231-245.

Jacquet, J., \& Stedman, R. (2011). Natural gas landowner coalitions in New York State. Journal of Rural Social Sciences, 26, 62-91.

Johnson, G. B., \& Crisp, B. F. (2003). Mandates, powers, and policies. American Journal of Political Science, 47(1), 128-142.

Kemp, R. (1985). Planning, public hearings, and the politics of discourse. Critical Theory and Public Life, edited by John Forester, MIT Press, pp. 177-201.

Kenneally, M., \& Mathes, T. (2010). Natural gas production and municipal home rule in New York. January/February: New York Zoning Law and Practice Report.

Lemos, M. C., \& Agrawal, A. (2006). Environmental governance. Annual Review of Environment and Resources, 31, 297-325.

Leong, C., \& Howlett, M. (2017). On credit and blame: Disentangling the motivations of public policy decision-making behaviour. Policy Sciences, 50(4), 599-618.

Lubell, M. (2004a). Collaborative environmental institutions: All talk and no action? Journal of Policy Analysis and Management, 3, 549-573.

Lubell, M. (2004b). Collaborative watershed management: A view from the grassroots. Policy Studies Journal, 32(3), 341-361.

Marshall, G. (2008). Nesting, subsidiarity, and community-based environmental governance beyond the local scale. International journal of the Commons, 2(1), 75-97.

McGraw, K. M. (1990). Avoiding blame: An experimental investigation of political excuses and justifications. British Journal of Political Science, 20(1), 99-142.

McGraw, K. M. (1991). Managing blame: An experimental test of the effects of political accounts. The American Political Science Review, 85(4), 1133-1157.

Mintzberg, H., Raisinghani, D., \& Theoret, A. (1976). The structure of "unstructured" decision processes. Administrative Science Quarterly, 21(2), 246-275.

Negro, S. (2012). Fracking wars: Federal, state, and local conflicts over the regulation of natural gas activities. Zoning and Planning Law Report, 35(2), 2-16.

Rahm, D. (2011). Regulating hydraulic fracturing in shale gas plays: The case of texas. Energy Policy, 39(5), 2974-2981.

Reed, M. S. (2008). Stakeholder participation for environmental management: A literature review. Biological Conservation, 141(10), 2417-2431.

Rein, M., \& Schön, D. A. (1977). Problem setting in policy research. In C. H. Weiss (Ed.), Using Social Research in Public Policy Making (pp. 235-251). Lexington: Lexington Books.

Rowe, G., \& Frewer, L. J. (2000). Public participation methods: A framework for evaluation. Science, Technology and Human Values, 25(1), 3-29.

Rubin, H. J. (1988). Shoot anything that flies; claim anything that falls: Conversations with economic development practitioners. Economic Development Quarterly, 2(3), 236-251.

Rugh, P. (2012). As Cuomo weighs fracking, two small towns highlight the risks. The Examiner, May 2. https://article.wn.com/view/2012/05/02/As_Cuomo_weighs_fracking_two_smalltowns_hghligt_the_ risks/. Accessed August 2, 2016.

Sharp, E. B. (1984). "Exit, voice, and loyalty" in the context of local government problems. Western Political Quarterly, 37(1), 67-83.

Sharp, E. B., Daley, D. M., \& Lynch, M. S. (2011). Understanding local adoption an implementation of climate change mitigation policy. Urban Affairs Review, 47(3), 433-457.

Smith, M. F., \& Ferguson, D. P. (2013). "Fracking democracy": Issue management and locus of policy decision-making in the Marcellus Shale gas drilling debate. Public Relations Review, 39(4), 377-386.

Smith, P. D., \& McDonough, M. H. (2001). Beyond public participation: Fairness in natural resource decision making. Society \& Natural Resources, 14(3), 239-249.

Teodoro, M. P. (2011). Bureaucratic ambition: Careers, motives, and the innovative administrator. Baltimore: The John Hopkins University Press.

Tiebout, C. (1956). A pure theory of local expenditures. Journal of Political Economy, 64(5), 416-424.

Towers, G. (2000). Applying the political geography of scale: Grassroots strategies and environmental justice. The Professional Geographer, 52(1), 23-36. 
Vigoda, E. (2002). From responsiveness to collaboration: Governance, citizens, and the next generation of public administration. Public Administration Review, 62(5), 527-540.

Walsh, P. J., Bird, S., \& Heintzelman, M. D. (2015). Understanding local regulation of fracking: A spatial econometric approach. Agricultural and Resource Economics Review, 44(2), 138-163.

Weiss, J. A. (1982). Coping with complexity: An experimental study of public policy decision-making. Journal of Policy Analysis and Management, 2(1), 66-87.

Zahran, S., Brody, S. D., Vedlitz, A., Grover, H., \& Miller, C. (2008). Vulnerability and capacity: Explaining local commitment to climate-change policy. Environment and Planning C: Government and Policy, 26(3), 544-562.

Zhang, Y., \& Feiock, R. C. (2010). City managers' policy leadership in council manager cities. Journal of Public Administration Research and Theory, 20(2), 461-476.

Zirogiannis, N., Alcorn, J., Piepenburg, J., \& Rupp, J. (2015). I want in on that: Community level policies for unconventional gas development in New York. Agricultural and Resource Economics Review, 44(2), 164-194.

Publisher's Note Springer Nature remains neutral with regard to jurisdictional claims in published maps and institutional affiliations. 